\title{
PUBLIC PERCEPTION TOWARDS PTI GOVERNMENT IN KHYBER PAKHTUNKHWA: AN ANALYSIS OF THE EDUCATION SECTOR
}

\author{
Shaukat \\ Lecturer, Department of Political Science, Abdul Wali Khan University Mardan \\ shaukat@awkum.edu.pk \\ Jehangir Alam \\ Lecturer, Department of Political ScienceUniversity of Chitral, Chitral, \\ Jehangiralam@uoch.edu.pk

\section{Sanaullah} \\ Demonstrator Department of Political Science, Abdul Wali Khan University Mardan \\ Sana-ullah@awkum.edu.pk
}

\begin{abstract}
PTI came to power with an "agenda of change" in K.P that has been marred by many problems, including low literacy rate and poor quality of education. There is a growing demand in public for the provision and uplifting of the standard of education, particularly in the province of Khyber Pakhtunkhwa. An analysis has been made of the PTI government policies and reforms in education sector and to evaluate public perception regarding these initiative that the government has introduced in education. The present government is keen in its approach to bring uniformity in the curricula for the whole province. This study is very significant as it will study the reform policies of the PTI government from the prism of good governance and will also analyse the opinion and point of view of the people of Khyber Pakhtunkhwa towards these reforms. It will measure the perceptions of the people and their level of satisfaction/ non-satisfaction from the government. An effort has been made to bring the attention of the government and policy makers.
\end{abstract}

Key Words; MDGS, Public Perceptions, Governance, Reforms, Literacy

\section{INTRODUCTION}

Governance is a process that determines the fate of a nation. It is "the process of decision-making and the process by which decisions are implemented (or not implemented)" (Kakar, 2016; Sheng, n.d.). Its contextual meaning differs, depending on the case in hand. Government is one of the important actors in governance. While analysing governance, the focus should be on both formal and informal actors that are included in making of the policy and its implementation. The most commonly considered characteristics for good governance includes accountability, transparency, participatory, consensus oriented, equity, inclusiveness, efficiency, responsiveness, and the rule of law. While making a decision, minority's views are also considered and respected and the demands of marginalized and vulnerable community of the society is also accommodated, keeping in mind both the present and future needs of the society (IFAD, 1999; Sheng, n.d).

In Pakistan, the culture of good governance seems bleak and dismal. Since its inception, it has not been achieved due to various factors which include repeated military dictatorship as a result of political instability, lack of accountability and transparency resulting into corruption, and the absence of rule of law that has left the country at an appalling state of poor governance (Kakar, 2016).

Khyber Pakhtunkhwa is faced by a matrix of governance problems ranging from a large scale corruption, low literacy rate, lack of health facilities, militancy, and poverty that needs serious attention from the government. The current government of PTI came to power with an agenda of change and introduced reforms in different sectors/departments under the charter of governance, aimed at improving governance in the province and hence, improving the quality of public services to the people.

\section{The Educational Policy}

Khyber Pakhtunkhwa, as one of the most strategically significant province of Pakistan, is playing an important role in the progress and development of the country. In terms of education, seven million 
out of 26.62 million people in KP are illiterate. Beside several challenges faced by KP, the vision 2030 is a commitment of greater highest (Mustafa, 2012).

The education policy of the KP along with its different projects and development is the implementation of national education policy 2009. The $18^{\text {th }}$ amendment strengthens the education department which is now changing itself to perform additional responsibilities. The article 25-A of the $18^{\text {th }}$ amendment made education compulsory for age 5 to 6 years, the government of KP also approved vision education reforms for providing quality education. The policy of the government included practical proposal for provision of quality education, performance based recognition, peaceful working conditions, teacher training, the medium of instruction, quality text books, effective curriculum establishment of an independent education commission. The policy also includes filling up all vacant posts of teachers on merit, quality assessment, revamping curricula, text book and boards and addressing the problem of private sector educational institute, management and governance of school (The Express Tribune, 2014).

\section{Challenges}

Beside several educational developments, there are various challenges to education in KP. There is a dire need for early childhood education policy to be incorporated into a regular education budget. There is lack of specialised teachers in public sector institutions available for this level of education. Gender and regional disparity in enrolment pattern is also widened. Urban enrolment is higher than the rural enrolment. Same like female enrolment is lesser than male enrolment. There are several considerable variations in the enrolment within the province. The situation for female education is more than worse in the rural districts of KP. Technical and educational sectors are also suffering from the inadequacy of resources; weak training resulting into low capacity, and market linkages, plus special education is also an unmaintained sector in education sector. The rural population is greatly disadvantaged to assess these institutions. Special education is still running on charity basis. Nonformal education and adult literacy is also suffering from a lack human resource and finance. The situation is further aggravated by the difficulty in mainstreaming and a lack of access to quality education, especially in public institutions. The political will is not up to the mark to improve education (Mustafa, 2012).

\section{Achievements}

In recent years, the government of KP addressed many challenges faced by education department. Through elementary education foundation, the government has embarked upon a policy to promote private participation in educational provisions along with public private partnership. The provincial government in provincial budget of 2011-12 made an increase of 32.81\% as compared to previous budget, the number of schools has also been increased from 26247 to 27419 . Similarly, enrolment has also increased from 3.534 to 3.597 million students. Higher education has also scaled new achievement during the year 2010-11, new universities and colleges were established. The establishment of higher education regulatory authority has created positive impacts on the regulatory achievements for higher education in private sector (Pakistan Economic Survey, 2012-13).

Education sector is one of the most important sectors of the state. Its starts from early childhood stage to the higher education, each stage has its own importance and is consisted of specific time. In KP, education sector is consisted of many stages. It begins with the early childhood education. This stage is consisted of those children who are three to five years of age. This is a stage when the overall worldview of a child is developed, though no formal education, in the form of text book examination etc., is given however, the overall environment is designed in such way that the child learned a lot through observation. In developed countries, this stage has been given special attention, while in Pakistan, there is no public policy till early 1990. However, that was in 2009 that Pakistan identified three areas for the improvement of early childhood education. These were wider participation, better quality and improved governance (Pakistan Education for All, 2015).

The second stage is known as primary education, it is designed in a manner that by 2015 , a full course of primary education must be ensured to all boys and girls. It means elimination of gender disparity at primary level. The 2015 goal was not achieved by Khyber Pakhtunkhwa government. Middle level education is also a part of educational sector; the official age of this level of education is considered from 6 to 10 years. Secondary education is also ensured by article 37(B) of our 
constitution. Free secondary education was promised constitutionally; however, this target seems far away from accomplishment and apart from it, the curricula and examination system creates a gap between the children of poor and rich families. Private school offer foreign schedule which is out of the reach of children of the poor families. College and university education is also faced with basic challenges. Posting of college teacher staff is mainly affected by political pressure. This adversely affects the quality of education in our colleges. Similarly, technical and vocational education is also faced with various problems. Pakistan has a huge population and the need is to provide technical education to these people. The need is to skilfully develop the abilities of our population, and the industry, electrical, mechanical and timber sector. There are some areas in education which needs attention of KP government; the policy action for it has been designed by the government. All we need is to implement this policy. In early childhood education level, there is need of a proper training to the teacher. Moreover, the students need to be involved in different activities (Ashraf \& Ismat, 2016).

Availability of basic facilities like drinking water and electricity are of also great importance. There is need of reducing dropout. This will help the province to increase literacy rate, there is a need of providing second shift education to those children who are the only earning hands of their families. This will help the province to improve the literacy rate which is $65 \%$ for male and $28 \%$ for female, according to Pakistan Social and Living Standards Measurement report 2010-11 (PSLM , 2014). Thus, there is also a greater need to achieve all the educational goals specified by the government.

\section{Status of MDGs}

\section{International Convention}

During 2005-6 of MICS KP bureau of Statistics UN designated 18 targets and 48 indicators in each of 8 goals. KP government adopted 16 targets and 37 indicators, the KP MDGR 2005 cover 7 goals and 32 indicators (Pakistan Millennium Development Goals, 2013). The situation of education has been worsened by security issues and large scale afghan refugees.

KP Government Formulated Strategy for 2010-2017

1. Public goods provision for poverty reduction.

2. Improving competition for quality.

3. Improving technical education.

4. Facilitating the private sector.

\section{MDGS 2}

Achieving universal primary education, the literacy rate is still $50 \%$ less than national percentage of literacy. Female literacy rate is $31 \%$. Some of the districts have higher rate like Abbottabad $72 \%$ and some have low literacy rate, in addition to the poverty in Pakistan which has further aggravated the issue. Gender disparities discourage girls from education. Teacher's student's relationship and child labour also prevent children from education. Religious interpretation and lack of commitment also affect the education. Therefore, in order to address these issues and achieve the designated objectives, KP government has made certain strategies (Pakistan Millennium Development Goals, 2013).

\section{Strategies}

EFA (education for all) needs to be implemented, and introduction of childhood education at primary school level is necessary in order to improve gender equality. Primary education must be free for all. Education budget is to be increased and scholarship for female to be introduced. School monitoring must be introduced and diversified as well as Information technology must be introduced in the province.

Education has been declared the first priority by the KP government. The government has taken the initiative to improve the overall status of education in KP. Therefore, KP government signed EFA and MDGs agreements. EFA has certain goals i.e. early childhood education, completion of free primary education, life skills and adult education, eliminating gender disparity and improving overall education status. The goal is to achieve universal primary education in KP, and for the said purpose, changes have been made in the curriculum. Kachi childhood years have been included in primary 
education. Government urged to educate predicated children of 6.41 million and stop the drop out ratio (Hussain, 2015).

\section{Educational Policy in Khyber Pakhtunkhwa}

Education has been a subject of debate since the inception of Pakistan. Various policies have been advised to strengthen the educational sector in Pakistan and a major step in this direction was the inclusion of article $25-\mathrm{A}$ in the 1973 constitution, through the $18^{\text {th }}$ amendment. It ensures the provision of compulsory education to all the children from age 5 to 16 years. However, its implementations have not been done at provincial level. After the insertion of article 25-A, provinces need to devise new laws and legislative revisions of the past, so as to streamline the curriculum and text books. It should also take administrative measure for improvement of the policy. The province needs to revise the rules of business and most importantly, it should revise policy framework for private sectors. Provinces should strengthen its directorate of curriculum and provincial text book (Mustafa, 2012). However, with this new education policy, the education departments have taken some solid steps for improvement of access to education. Schools have been built, teachers have been hired, and quality of education has been improved. Another major achievement is the separation of the teaching and management cadre. Governing bodies for higher secondary school have been established and service structure for teachers has now been in place. Capacity building for teachers and data of non-governmental schools has been compiled (Pakistan Education for All, 2015).

The subgroup sample of population, the one having the attributes of the total population, was generalized (Sekaran, 2003). For the purpose of sampling in this study, the technique of proportionate stratified random sampling was used. From different respondent groups, based on their real representatives from all related strata's, the study population was divided into four strata, and then for collection of data were chosen randomly.

\section{RECOMMENDATIONS}

- To clear and address the present problems of educations, strategies should be based on the local levels rather than central level. It should be decentralized.

- Substantive investments should be made with realized targets plans and strategies should be such as to suit the practical needs of the situation and location.

- The religious leaders and opinion makers should be taken into confidence and brought within the orbit of government policy.

- This will help to achieve the objectives. Keeping in view the millennium development goals, the educational institutions need to be provided with advance learning tools.

- The gap between boys and girls' schools should be abridged.

- In order to provide more access to higher education, more colleges should be opened

- Budgetary allocation for education should be increased by $8 \%$ of the GPD as the standard of $\mathrm{UN}$.

- There must be a uniform system of education which help in fostering harmony and avoid ideological differences.

- Madrasahs should be brought under state regulation and be provided proper attention.

- Provincial education secretariat should pay heed towards the implementation of article 18 of the constitution.

- The provincial government should comply with article 25 and provide budgetary consideration to make free compulsory education.

\section{CONCLUSION}

PTI government in Khyber Pakhtunkhwa has introduced various reforms in the education sector. These reforms were measured against various standards and variables to evaluate public perceptions regarding these initiatives that the government introduced in education. People's perceptions were assessed against variables like curricula, teacher's attendance and primary education, quality of education and MDGs of the United Nations. The findings revealed that the province has shown improvement in primary education. It is revealed that the government is keen to impart primary 
education to both girls and boys alike. The government has made all the necessary resources available for the improvement of primary education. The curriculum is designed to meet the demands of the modern times and is keen in its approach to bring uniformity in the curricula for the whole province. PTI government is following the MGDs set by the United Nations in both Health and Education Sectors.

\section{REFERENCES}

Ahmad, V. \& Cathal, O.D. (2010). Global Economic Crises and Poverty in Pakistan. International Journal of Microsimulation, 3(1), 127-129.

Asad, M.A. \& Mehboob, A. (2011). Growth and Consumption inequality in Pakistan. Pakistan Economic and Social Review, 49(1), 69-89.

Asghar, M.U. (2013). Governance Issues in Pakistan: Suggested Action, Strategic Research Associate at Institute for Strategic Studies, Research and Analysis (ISSRA), National Defence University, Islamabad.

Cheema, A.R. \& Maqbool, H.S. (2012). Poverty, income equality and growth in Pakistan: A pooled regression analysis. Lahore Journal of Economics

Cohen, P.S. (2010). The future of Pakistan. The Brooking Institution.

Graff, W. (2010). Beyond Madrasas: Assesing the links between education and Militancy in Pakistan. The journal of Brooking Institution

Hyden, G., Court, J., \& Mease, K. (2004), Making Sense of Governance. In Boulder, Co \& Lynne

Reiner IFAD. (1999). Good governance: an overview. International fund for agricultural development Executive Board - Sixty-Seventh Session, Rome.

Irshad, M. (2011). Terrorism in Pakistan: Causes and Remedies, The Dialogue

Jalalzai, M.K. (2000). The Crisis of State and Security in Pakistan. Jasim Publication/Dua Publication. 